\title{
Pode o amor ser isto
}

\section{Emília Costa}

Titulo: Os meus sentimentos. Autor: Dulce Maria Cardoso. Espectáculo: Mónica Calle. Assistência de encenação: Mónica Garnel. Cenografia e interpretação: Mónica Calle. Luz: José Álvaro Correia. Produção: Casa Conveniente/Culturgest. Local e data de estreia: Culturgest, Lisboa, 3 de Abril de 2013.

Titulo: Noites brancas 3. ${ }^{a}$ parte. Espectáculo: Mónica Calle. Luz: Daniel Worm. Assistência de luz: Marta Simões e Caldino Alberto. Interpretação: Alexandra Gaspar, Candé, Fábio Silva, Francisco Villalobos, Hugo Bettencourt, José Vitorino, Luís Afonso, Luís Fonseca, Mário Fernandes, Mónica Calle, Mónica Garnel, Rita Só, René Vidal, Simão Fortes, Sófia Vitória e Wilson Magalhães. Produção: Casa Conveniente/ Maria Matos Teatro Municipal. Local e data de estreia: Maria Matos Teatro Municipal, Lisboa, 9 de Julho de 2013.

"[...] bravura, nobreza e entrega". Que ninguém se iluda, os cobardes não têm acesso à beleza. Rui Chafes (2012: 42)

Entre Abril e Julho de 2013, os palcos de Lisboa tiveram a oportunidade de assistir a dois espectáculos de Mónica Calle: Os meus sentimentos e Noites brancas. 0 primeiro, uma co-produção da Casa Conveniente e da Culturgest, tinha prevista a duração de cinco horas, porém, na realidade, com os três intervalos que temporariamente 0 interromperam, durou quase sete horas. 0 segundo, inserido no 30. Festival Internacional de Teatro de Almada, fez parte de uma trilogia de espectáculos, com duração total de 5 horas. A terceira parte foi atribuída a Mónica Calle e teve a duração de três horas ${ }^{1}$.

Numa época em que o tempo nos foge por entre os dedos, quantos de nós, espectadores afundados em compromissos, em preocupações infindáveis, possuem ainda a capacidade de se deixar ficar, de saborear o vagar das palavras ditas e de se deixar encantar com a beleza dos corpos transpirados? Quantos de nós conseguem, sem hesitações, sem sentimentos de culpa, entregar-se e esquecer o inexorável passar do tempo?

A entrega é, na realidade, a chave do enigma. Não é possivel participar em qualquer um destes dois espectáculos, independentemente da posição que se ocupe (actor ou espectador), sem se estar disponivel para a entrega. 0 espectador que permanece entrega-se. A actriz (Mónica Calle) em Os meus sentimentos ou os actores (Alexandra Gaspar, Candé, Fábio Silva, Francisco Villalobos, Hugo Bettencourt, José Vitorino, Luis Afonso, Luis Fonseca, Mário Fernandes, Mónica Calle, Mónica Garnel, Rita Só, René Vidal, Simão Fortes, Sofia Vitória e Wilson Magalhães) em Noites brancas, despojados, sem artificios, conseguem resistir tantas horas em palco, em exigentes representações, porque se entregam.

A energia que perpassa nessa entrega é profunda. "Há alguém que me queira abraçar?" Esta é a interpelação da actriz (Mónica Calle) em Os meus sentimentos e do actor (José Vitorino) em Noites brancas. Um silêncio pesado invade a sala. A vontade de ir, de corresponder a esse apelo, a essa dor e, no entanto, o medo, o medo de quem pagou bilhete apenas para assistir, sentado, silencioso e imóvel, "quando nos pomos numa vida não sabemos ter outra" (Cardoso 2005: 28). Em Noites brancas, porém, uma espectadora rompe o medo. 0 abraço intenso arrepia. A nossa solidão ali exposta. Somos infinitamente pequenos perante a grandeza daquele abraço.

0 que há nestes espectáculos que nos enfeitiça? Calle procura a essência, sem subterfúgios, sem máscaras. Haverá teatro sem máscaras?

Em Os meus sentimentos, Calle, sozinha em palco, durante cerca de 6 horas, interpreta e lê um livro, porém, não se trata de um espectáculo de leitura. Calle interpreta Violeta, a personagem principal do livro que foi escrito por Dulce Maria Cardoso, cujo título deu nome ao espectáculo. As palavras que são pura poesia de Dulce Maria Cardoso ganham vida na interpretação de Calle. A actriz expõe o corpo, o sexo, leva-se à exaustão. Corre, dança, chora, extenua-se. E mostra-se. É o seu rosto, o seu suor, a sua dor, ali, exactamente ali, um palmo à nossa frente. Calle revela-se. Entrega-se num acto de amor, "pode o amor ser isto, pode o amor" (Cardoso 2005: 41).

0 espectáculo inicia-se e termina com música, primeiro Meio-termo/Corpos de Elis Regina, depois Nice ' $n$ ' rough de Tina Turner. A música percorre todo o espectáculo, integra-se nele, numa excelente selecção, que inclui Jonhy Cash, P.J. Harvey e Nirvana.

A música e o magnífico jogo de luzes e sombras, num irrepreensivel trabalho de José Álvaro Correia, intensificam o ambiente decadente e dramático que ressoa das palavras de Calle. A luz brinca com o destino de Violeta, enegrecendo Calle à medida que o espectáculo avança. A actriz dança com a sua própria sombra, quantas mulheres existem numa?

Violeta, a personagem, sabe que nasceu para a infelicidade. A obesidade que a separa dos outros é simultaneamente um infortúnio e uma arma, a sua mais poderosa arma. Violeta exibe as suas banhas, mostra a carne que há nela. E este é o meu corpo, diz Calle no início do espectáculo. Corpo e espírito. Pai-nosso que estais no Céu. 0 corpo é carne, sangue, sexo. 0 espírito é energia, é vontade de transcender. Poderão corpo e espírito
A primeira parte foi atribuida a Sofia Dinger e a segunda a Paula Diogo

Emilia Costa é licenciada em Direito pela Faculdade de Direito da Universidade de Lisboa e mestranda em Estudos de Teatro na Faculdade de Letras da mesma Universidade. É autora das adaptações para teatro do livro Timbuktu de Paul Auster, levado à cena no Teatro da Trindade; e do livro $O$ jogador de Dostoievski, levado à cena no São Luiz Teatro Municipal. Participou no projecto Curtas Mostra teatral de peças de curta duração, em 2008, 2010 e 2012, com os originais Maria Jesuína a Mikas, Desencontros lunares e Estranhamentos, todos encenados por Bruno Bravo. É também membro da Associação Portuguesa dos Críticos de Teatro. 

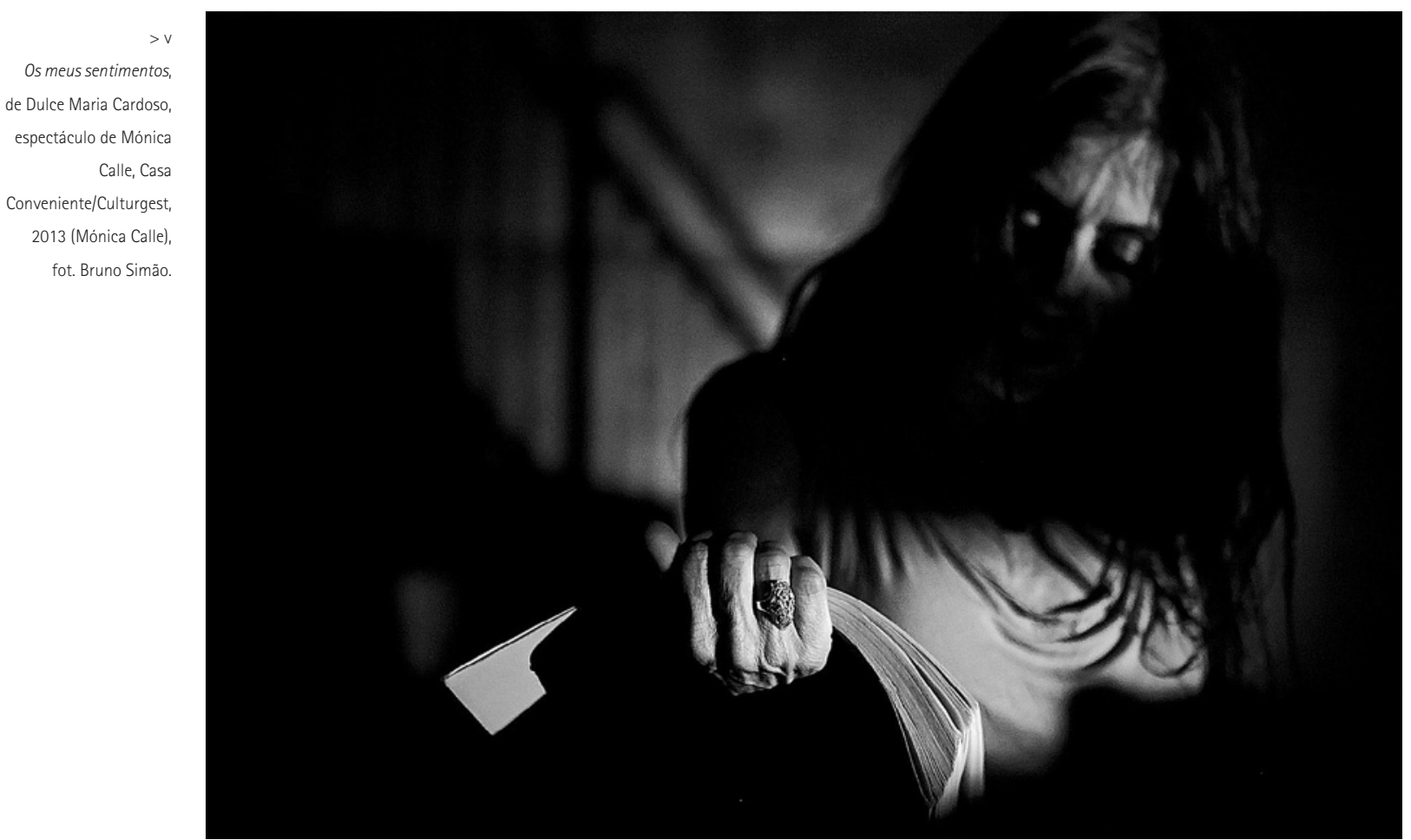

pacificamente coabitar? Calle busca essa união num ousado início onde oração e masturbação se interpenetram. Este é o meu espírito e este é o meu corpo. Não existem fronteiras. 0 sexo também transcende.

Mas nós, espectadores acabados de chegar da rua, dos empregos, da familia, empedernidos nas nossas inabaláveis personagens, ainda não conhecemos Violeta. Ainda não sabemos que ela "caça" homens nos parques para camionistas nas estações de serviço, para saciar a carne, essa carne que prolifera por todo o lado. Ainda não sabemos que não tem amigos, que os pais e a filha sentem nojo dela. Que nunca ninguém a amou. Não sabemos quanto Ihe dói a solidão. E, por isso, exactamente por isso, é violento o início. Uma mulher de pé, à nossa frente, ao alcance dos nossos braços, expondo o seu sexo, masturbando-se para nós, olhando-nos enquanto se masturba. Suportamos? Se suportarmos ascendemos à transcendência, "quando nos põem numa vida temos de a levar para todo o lado" (Cardoso 2005: 139).

À medida que o espectáculo avança, o tempo passa sem que nos apercebamos. Os olhos seguem Violeta/Calle nessa embriaguez de sentir. Calle e Violeta não se distinguem, confundem-se num único ser; e, no entanto, a actriz não tem quaisquer semelhanças físicas com a personagem. 0 verdadeiro actor é mágico, leva-nos a ver para além do tangivel. E a escuridão avança ao mesmo ritmo das horas. Sabemos que o Destino é a morte. Mas mesmo assim não deixamos de nos surpreender. E quando o livro se fecha, são quase três horas da madrugada. Será possivel?

Porém, o espectáculo ainda não terminou. A actriz continua em palco. A música permanece. Quer dançar? Os espectadores saem dos seus lugares e começam a dançar. A actriz e os espectadores todos juntos, do mesmo lado, no palco, sem paredes a separá-los. A sinergia resultante do espectáculo prolonga-se, é possivel prolongar-se mesmo depois do livro se fechar. Até quando?

Em Noites brancas, Calle prossegue a sua busca,

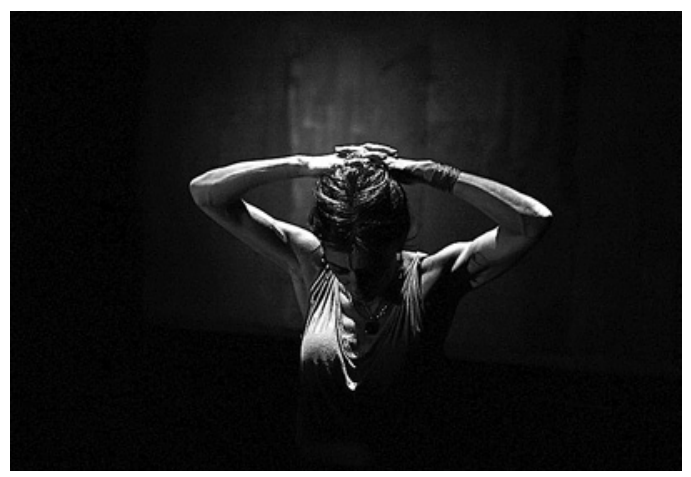

intensifica-a. 0 corpo. A beleza do corpo. As suas potencialidades. 0 actor é bailarino, contorcionista, equilibrista. Poderá o corpo transcender-se?

A música de Alan Lomax (numa brilhante recolha de músicas de prisão dos negros do Mississípi), de Stravinsky, de P.J. Harvey, de Jacques Brel, de Nina Simone, enquadrada por uma perfeita arquitectura de luzes, a cargo de Daniel Worm, que privilegia a penumbra, revela-nos verdadeiros quadros humanos de indelével beleza. 0 suor que brilha no corpo dos actores/bailarinos e thes destaca os músculos é um elemento cénico. A corda com que ritmadamente batem no chão ao mesmo tempo que saltam, simulando os trabalhos forçados que os negros americanos efectuavam no Mississipi é pura coreografia. 0 corpo humano é o centro da interdisciplinaridade. É nele que se fundem o actor, o bailarino, 0 artista de circo. E, associada à vitalidade do corpo, a confiança dos corpos uns nos outros, sem a qual este espectáculo não poderia ter acontecido. A pirâmide humana depende de todos e de cada um. 0 actor não age por si, para si, age de e para o grupo.

À cadência da música, os corpos fundem-se, agitamse, equilibram-se, arriscam o impossível. Calle a encenadora coreógrafa. Apesar da evidente aproximação de Calle à dança, a palavra dita mantém a sua fundamental 


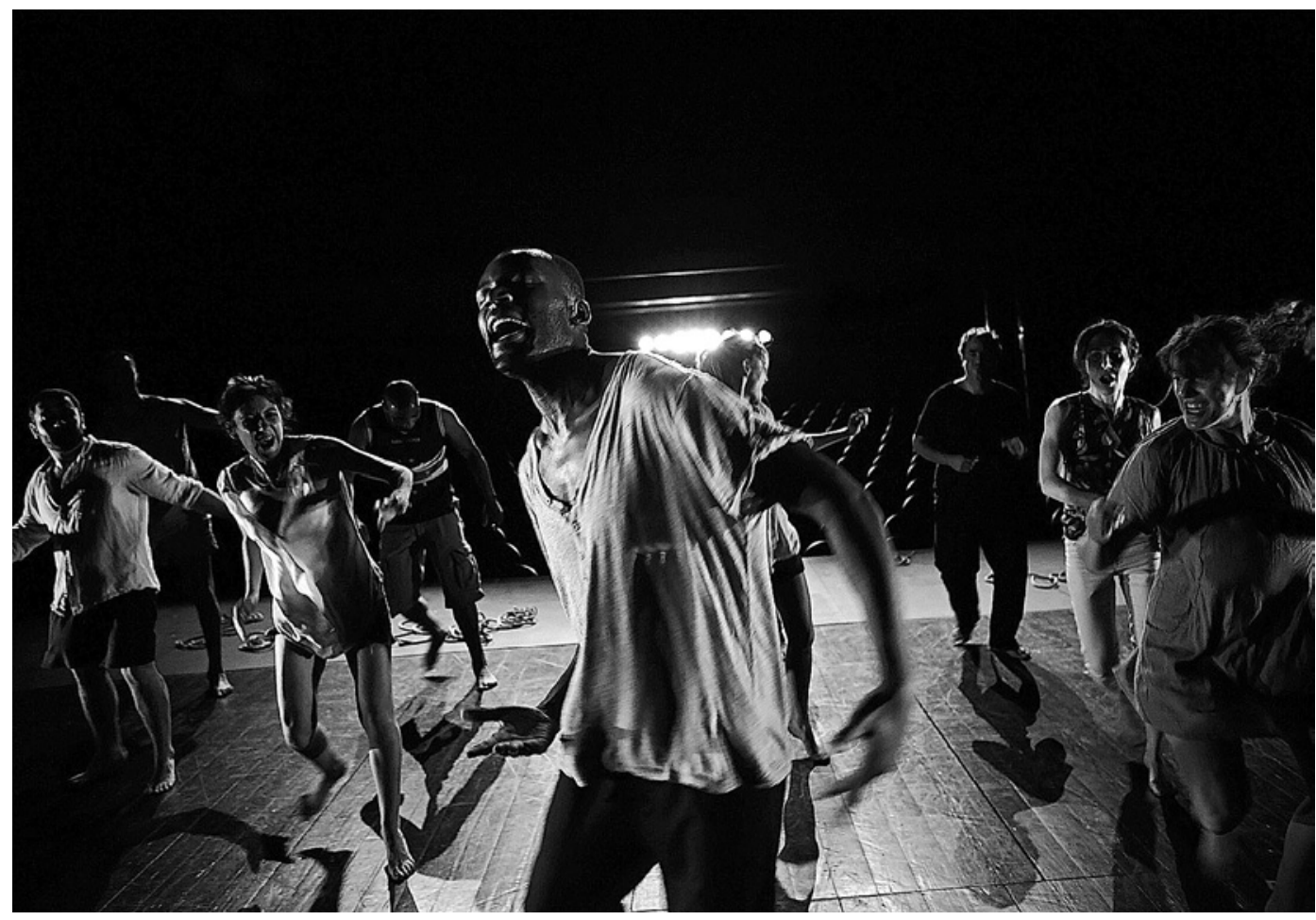

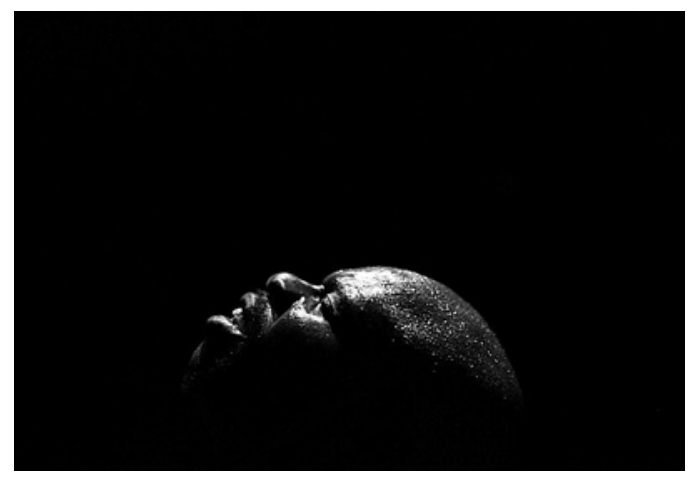

importância. Excertos dos livros 0 vestido vermelho de Stig Dagerman, 0 santuário de William Faulkner, Assim falava Zaratustra de Nietzsche, The crack-up de F. Scott Fitzgerald, Macbeth de Heiner Müller, Os meus sentimentos de Dulce Maria Cardoso, Entre o céu e a terra de Rui Chafes e Diário 1941 - 1943 de Etty Hillesum, ecoam na escuridão dos corpos transpirados pelo esforço físico a que estão sujeitos. Quando o actor (Luís Afonso) inicia o espectáculo, esclarece-nos, desde logo, nas palavras de Stig Dagerman, que aquele não é o espaço para a mediocridade, para o "mundo dos cães dos pequenos sentimentos, dos pequenos prazeres, dos pequenos pensamentos" (Dagerman 1958: 323), que ali é o lugar da busca pela beleza, com bravura, nobreza e entrega. Por isso, no final, em grande apoteose, surge um escadote por onde cada actor sobe para depois se atirar de costas e ser agarrado pelos outros, por todos os outros que, juntos, o salvam: "'bravura, nobreza e entrega.' Que ninguém se iluda, os cobardes não têm acesso à beleza!"

E uma vez mais, depois de o espectáculo terminar, os espectadores são convidados a partilhar o palco, a dançar ao som da música, que continua a tocar, e ainda a atiraremse de costas do escadote para serem agarrados pelos actores.

Os meus sentimentos e Noites brancas não são espectáculos que possam ser vistos com a indiferença de

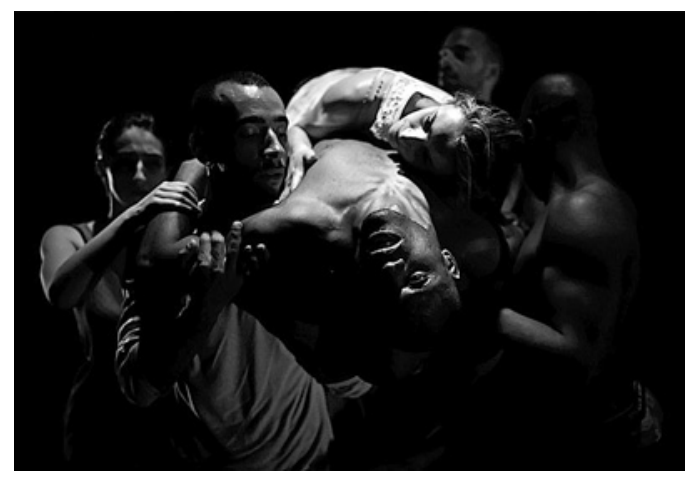

quem apenas procura distracção. Implicam um compromisso, uma aceitação, um risco, uma entrega. 0 fascinante mistério que neles se encerra reside na circunstância de Mónica Calle e os seus actores, com um candeeiro, um livro, um escadote e umas cordas, cercados por músicas e luzes, conseguirem envolver-nos numa espécie de magia, numa espécie de encantamento, como se a verdade e a vida estivessem ali, exactamente ali.

Sacrifício, entrega, autenticidade. Só um acto de amor pode ser tão perfeito.

\section{Referências bibliográficas}

CARDOSO, Dulce Maria (2005), Os meus sentimentos, Lisboa, Asa. CHAFES, Rui (2012), Entre o céu e a terra, Lisboa, Documenta. DAGERMAN, Stig (1958), O vestido vermelho, trad. Irene Lisboa, Lisboa, Estúdio Cor.

FAULKNER, William (1973), Santuário, trad. Fernanda Pinto Rodrigues, Lisboa, Minerva.

FITZGERALD, F. Scott (2011), The crack-up e outros escritos, trad. Miguel Serras Pereira, Lisboa, Relógio d'Água.

NIETZSCHE (1994), Assim falava Zaratustra, trad. Alfredo Margarido, Lisboa, Guimarães, $10^{\mathrm{a}}$ edição. $\wedge<>$

Noites brancas,

espectáculo de Mónica Calle, Casa Conveniente/Teatro Municipal Maria Matos 2013 ( $\wedge$ José Vitorino, Luis Afonso, Mónica Calle, Simão Fortes, Wilson Magalhães, Rita Só, Luis Fonseca, Alexandra Gaspar, Mónica Garnel e Bruno Candé Marques; $<$ Bruno Candé Marques: > Sofia Vitória, Fábio Silva, René Vidal, Rita Só Luis Afonso e Bruno Candé Marques), fot. Bruno Simão. 